\title{
Article \\ Phosphine-Free-Synthesized ZnSe/ZnS Core/Shell Quantum Dots for White Light-Emitting Diodes
}

\author{
Nyamsuren Byambasuren ${ }^{1,2} \mathbb{D}^{-}$, Jiyeon Jo ${ }^{1,3}$, Hyungduk Ko ${ }^{4}$, Byeong-Kwon Ju ${ }^{3} \mathbb{D}$, Ji Young Byun ${ }^{5}$ and \\ Ho Seong Jang ${ }^{1,2, *}$
}

Citation: Byambasuren, N.; Jo, J.;

Ko, H.; Ju, B.-K.; Byun, J.Y.; Jang, H.S.

Phosphine-Free-Synthesized

ZnSe/ZnS Core/Shell Quantum Dots for White Light-Emitting Diodes.

Appl. Sci. 2021, 11, 10060.

https://doi.org/10.3390/app

112110060

Academic Editor: Vladimir M. Fomin

Received: 2 September 2021

Accepted: 18 October 2021

Published: 27 October 2021

Publisher's Note: MDPI stays neutral with regard to jurisdictional claims in published maps and institutional affiliations.

Copyright: (C) 2021 by the authors. Licensee MDPI, Basel, Switzerland. This article is an open access article distributed under the terms and conditions of the Creative Commons Attribution (CC BY) license (https:/ / creativecommons.org/licenses/by/ $4.0 /)$.
1 Material Architecturing Research Center, Korea Institute of Science and Technology, 5, Hwarang-ro 14-gil, Seongbuk-gu, Seoul 02792, Korea; nyamsuren.bb@kist.re.kr (N.B.); t18443@kist.re.kr (J.J.)

2 Division of Nano \& Information Technology, KIST School, Korea University of Science and Technology (UST), Seoul 02792, Korea

3 School of Electrical Engineering, Korea University, 145, Anam-ro, Seongbuk-gu, Seoul 02841, Korea; bkju@korea.ac.kr

4 Nanophotonics Research Center, Korea Institute of Science and Technology, 5, Hwarang-ro 14-gil, Seongbuk-gu, Seoul 02792, Korea; kohd94@kist.re.kr

5 Extreme Materials Research Center, Korea Institute of Science and Technology, 5, Hwarang-ro 14-gil, Seongbuk-gu, Seoul 02792, Korea; jybyun@kist.re.kr

* $\quad$ Correspondence: msekorea@kist.re.kr; Fax: +82-2-958-5599

\begin{abstract}
Blue-light-emitting ZnSe core (C) and ZnSe/ZnS core/shell (C/S) quantum dots (QDs) were synthesized with phosphine-free precursors by a thermal decomposition method in paraffin oil solvent and applied to QD-converted light-emitting diodes (LEDs). The optical properties of the synthesized ZnSe C and ZnSe/ZnS C/S QDs were characterized by absorption spectroscopy and photoluminescence spectroscopy. Additionally, the quantum efficiency of the QDs was investigated. Their structural properties were studied with X-ray crystallography and transmission electron microscopy. The ZnSe/ZnS C/S QDs showed deep-blue light peaking at $425 \mathrm{~nm}$. The blue-lightemitting ZnSe/ZnS C/S QDs were used as color-converting materials for near-ultraviolet LEDpumped blue LEDs and combined with yellow-light-emitting Zn-Cu-In-S/ZnS C/S QDs to fabricate white LEDs. The white LEDs showed warm white light $[(\mathrm{CIE} \mathrm{x}, \mathrm{CIE} y)=(0.4088,0.3987)], T_{\mathrm{C}}=3488 \mathrm{~K}$, and $\left.R_{a}=61.2\right]$. The results indicate that the $\mathrm{ZnSe} / \mathrm{ZnS} \mathrm{C} / \mathrm{S}$ QDs have good potential for white light application after further improvements to their optical properties.
\end{abstract}

Keywords: ZnSe/ZnS quantum dots; core/shell structure; blue LED; warm white LED

\section{Introduction}

Nanometer-scaled semiconductor materials called quantum dots (QDs) exhibit sizedependent electronic and optical properties due to the quantum confinement effect that is generated from spatially driven charge carriers, including holes and electrons in the ground and excited states [1-3]. Colloidal QDs are widely used in solar cells, biolabeling, light-emitting diodes (LEDs), $\mathrm{CO}_{2}$ reduction in water, and radioluminescent nuclear batteries [4-8]. In the last three decades, cadmium-based QDs have been popular, especially for light-emitting diode and display applications, due to their superior properties, such as size-controlled emission wavelengths over the entire visible light range, narrow and symmetric emission spectra, high photoluminescence (PL) quantum yields (QYs), and high photostability $[9,10]$.

However, there is now growing demand to develop cadmium-free QDs to reduce environmental harm and human health issues [11]. Related to these issues, cadmium-free green- or red-light-emitting materials, such as $\mathrm{InP}, \mathrm{CuInS}{ }_{2}$, Si-based QDs, and carbon dots, have been studied as alternatives to CdSe QDs [12-15]. Additionally, blue-light-emitting, ultra-small ZnSe-based QDs are one of the outstanding candidates for cadmium-free QDs and combining them with red- and green-emitting QDs can produce nonpoisonous white 
LEDs. ZnSe QDs were first synthesized by arrested precipitation, and more recently, using reverse micelles, precipitation in the presence of stabilizers, and heating-up and hot-injection methods $[16,17]$. In the hot-injection method, a reagent at room temperature is injected into the hot-reaction solution, producing a burst and homogenous nucleation, followed by slow growth, and annealing of the nanoparticles [18]. In early works, ZnSe QDs were synthesized using trioctylphosphine (TOP), trioctylphosphine oxide (TOPO), and tributylphosphine (TBP) as the solvent and stabilizing ligands $[19,20]$. Highly luminescent ZnSeTe-based QDs have been recently reported and applied to electroluminescent devices [21,22]. In those studies, TOP was also used to synthesize ZnSeTe-based QDs. In recent years, researchers have avoided using these toxic and expensive chemical reagents [23]. For example, in a previously reported method, zinc precursor was injected into paraffin oil containing Se-ODE at high reaction temperature [23].

In this study, we focused on synthesizing eco-friendly ZnSe-based QDs using phosphine-free precursors. The ZnSe C QDs were synthesized without phosphine precursors and the $\mathrm{ZnSe} / \mathrm{ZnS} \mathrm{C} / \mathrm{S}$ QDs were also synthesized with phosphine-free precursors via the one-pot synthesis method to improve their PL properties. There are many kinds of zinc source materials that can be used as zinc precursors, including zinc acetate, zinc stearate, diethyl zinc, and zinc oxide, depending on the synthesis environment [23-26]. In this study, we used $\mathrm{ZnO}$, which is soluble in acids and alkalis and can form complexes with ligands containing O-, $\mathrm{N}-$, or S-donor atoms [27]."Zn-oleate precursors were prepared by reacting $\mathrm{ZnO}$ and $\mathrm{OA}$ in paraffin oil. To synthesize high-quality and Cd-free, blue-emitting $\mathrm{ZnSe}$ QDs, we investigated the effects of reaction time and temperature on the PL properties of the ZnSe QDs.

In addition, we investigated the applicability of the $\mathrm{ZnSe} / \mathrm{ZnS} \mathrm{C} / \mathrm{S}$ QDs as colorconverting materials in optoelectronic devices such as LEDs. The phosphine-free synthesized blue-light-emitting ZnSe/ZnS C/S QDs were used as color-converting materials for near ultraviolet (nUV) LED-pumped blue LEDs. We also investigated the applicability of the ZnSe/ZnS C/S QDs to white LEDs. White LEDs are in high demand in the lighting and display fields because of their notable properties, including non-toxicity (no mercury), low power consumption, and long operating time $[28,29]$. For the first time, blue-light-emitting ZnSe/ZnS C/S QDs and yellow-light-emitting, Zn-doped CuInS 2 /ZnS C/S QDs were combined to fabricate white LEDs. The CuInS 2 -based QDs are suitable for white LED applications thanks to their high chemical stability, non-toxicity, tunable emitting wavelength, high luminous efficiency, large optical absorption coefficient, and large Stokes shift $[30,31]$. For these reasons, $\mathrm{CuInS}_{2} / \mathrm{ZnS}$-based QDs were adopted as the yellow-emitting materials. This study demonstrated that the $\mathrm{ZnSe} / \mathrm{ZnS}$ QDs are promising for use as a color-converting material for the fabrication of white LEDs.

\section{Materials and Methods}

Materials. To synthesize the $\mathrm{ZnSe} / \mathrm{ZnS} \mathrm{C} / \mathrm{S}$ QDs, zinc oxide (ZnO, 99.99\%), selenium (Se, 99.99\%), sulfur (S, 99.9\%), oleic acid (OA, 90\%), 1-octadecene (ODE, 90\%), hexane $(95 \%)$, chloroform $(95 \%)$, paraffin oil (analytical grade), acetone (analytical grade), and ethanol (EtOH, analytical grade) were purchased from Sigma-Aldrich. To synthesize the Zn-doped CuInS 2 /ZnS (ZCIS/ZnS) C/S QDs, copper (I) iodide (CuI, 99.999\%), indium acetate $\left(\mathrm{C}_{6} \mathrm{H}_{9} \mathrm{InO}_{6}, 99.99 \%\right)$, zinc chloride $\left(\mathrm{ZnCl}_{2}, \geq 98 \%\right)$, and 1-octanethiol (OTT, $\left.\geq 98.5 \%\right)$ were purchased from Sigma-Aldrich. Sodium oleate $\left(\mathrm{C}_{18} \mathrm{H}_{33} \mathrm{NaO}_{2},>97.0 \%\right)$ was purchased from Tokyo Chemical Industry.

Preparation of the $\mathrm{Zn}$ precursor. Two mmol of $\mathrm{ZnO}$, OA (4.5 g), and paraffin oil $(14 \mathrm{~mL})$ were loaded in a three-neck flask and heated to $300{ }^{\circ} \mathrm{C}$ for $30 \mathrm{~min}$ under argon flow to obtain a colorless, clear solution. After the reaction was finished, the temperature was cooled to room temperature and the resulting $\mathrm{Zn}$-oleate precursors were stored in an argon atmosphere.

Preparation of the Se precursor. Two mmol of Se and ODE $(20 \mathrm{~mL})$ were loaded in a three-neck flask and heated to $220^{\circ} \mathrm{C}$ for 180 min under argon flow. After the reaction was 
complete, the temperature was cooled to room temperature and the Se precursors were stored in an argon atmosphere.

Preparation of the $\mathbf{S}$ precursor. For preparation, $2 \mathrm{mmol}$ of $\mathrm{S}$ and ODE $(20 \mathrm{~mL})$ was loaded in a three-neck flask and heated to $150{ }^{\circ} \mathrm{C}$ for 30 min under argon flow. After the reaction was complete, the temperature was cooled to room temperature and the $S$ precursors were stored in an argon atmosphere.

Synthesis of the ZnSe/ZnS C/S QDs. ZnSe/ZnS C/S QDs were synthesized via a hot-injection method with a slight modification of the previously reported method [23]. Two $\mathrm{mL}$ Se precursor and $4.5 \mathrm{~mL}$ paraffin oil were loaded in a $50 \mathrm{~mL}$, three-neck flask and heated to $115^{\circ} \mathrm{C}$ for $30 \mathrm{~min}$ under a vacuum. After the solution was degassed, the reaction temperature was increased to $310^{\circ} \mathrm{C}$ under argon gas flow. Three $\mathrm{mL}$ of the $\mathrm{Zn}$ precursor solution was injected swiftly, and the temperature was kept at $310^{\circ} \mathrm{C}$ for $1 \mathrm{~h}$ for $\mathrm{ZnSe}$ growth. To grow the $\mathrm{ZnS}$ shell on the $\mathrm{ZnSe}$ core, $1 \mathrm{~mL}$ of the $\mathrm{S}$ precursor was slowly injected dropwise into the core solution at $310^{\circ} \mathrm{C}$. At intervals of $10 \mathrm{~min}, 1 \mathrm{~mL}$ of the $\mathrm{Zn}$ precursor was injected dropwise into the core solution. After aging for $30 \mathrm{~min}$ under argon gas, the synthesized $\mathrm{ZnSe} / \mathrm{ZnS} \mathrm{C} / \mathrm{S}$ QDs were washed with acetone, acetone/EtOH, and $\mathrm{EtOH}$ and finally dispersed in hexane for further study. Aliquots were taken at different time intervals to investigate growth kinetics by optical property characterization, such as UV-vis absorption and PL spectroscopy.

Synthesis of the Zn-doped CuInS 2 /ZnS (ZCIS/ZnS) C/S QDs. The ZCIS/ZnS C/S QDs were synthesized via a hot-injection method with a slight modification of the previous method [32]. Typically, a mixture of CuI ( $0.0238 \mathrm{~g}, 0.125 \mathrm{mmol}), \operatorname{In}(\mathrm{Ac})_{3}(0.1459 \mathrm{~g}, 0.5 \mathrm{mmol})$, Zn-oleate $(0.0126 \mathrm{~g}, 2 \mathrm{mmol})$, and $5 \mathrm{~mL}$ ODE was loaded in a three-neck flask and heated to $120{ }^{\circ} \mathrm{C}$ for $30 \mathrm{~min}$ under a vacuum. After the solution was degassed, the reaction temperature was increased to $230^{\circ} \mathrm{C}$ under argon gas flow. Three $\mathrm{mL}$ of OTT was swiftly injected, and the temperature was kept at $230{ }^{\circ} \mathrm{C}$ for $10 \mathrm{~min}$. A mixture of $\mathrm{Zn}$ stearate (2.5294 $\mathrm{g}, 4 \mathrm{mmol}), 4 \mathrm{~mL} \mathrm{OA}$, and $2 \mathrm{~mL}$ ODE was injected dropwise into the reaction flask. After the injection of the $\mathrm{Zn}$ precursors, the reaction temperature was increased to $240{ }^{\circ} \mathrm{C}$ and kept for $270 \mathrm{~min}$. The synthesized ZCIS/ZnS C/S QDs were washed with EtOH and dispersed in hexane for further use.

Fabrication of the ZnSe/ZnS QD-converted blue LEDs. To fabricate the nUV LEDpumped ZnSe/ZnS C/S QD-converted blue LEDs, the ZnSe/ZnS C/S QDs were redispersed in $3 \mathrm{~mL} \mathrm{CHCl}_{3}$ (optical density $\sim 1.892$ at $365 \mathrm{~nm}$ ) and the solution was mixed with silicone resin mixture (0.2074 g, OE-6630B:OE-6630A = 4:1, Dow Corning Co., Midland, MI, USA). The silicone-QD blend was degassed under a vacuum to remove the $\mathrm{CHCl}_{3}$ and air bubbles. The mixture of ZnSe/ZnS C/S QDs and silicone resin was coated on $395 \mathrm{~nm} n U V$ LEDs (non-molded, surface-mounted-device (SMD) type, $5.0 \times 5.0 \mathrm{~mm}^{2}$ ). The nUV LED packages, encapsulated with $\mathrm{ZnSe} / \mathrm{ZnS} \mathrm{C/S} \mathrm{QD}$-silicone resin, were cured at $60{ }^{\circ} \mathrm{C}$ for $60 \mathrm{~min}$, followed by curing at $110^{\circ} \mathrm{C}$ for $60 \mathrm{~min}$.

Fabrication of the blue and yellow QD-converted white LEDs. To fabricate the $\mathrm{ZnSe} / \mathrm{ZnS}$ and ZCIS/ZnS QD-converted white LED, the ZnSe/ZnS and ZCIS/ZnS QDs were redispersed in $\mathrm{CHCl}_{3}$ (optical density of $\mathrm{ZnSe} / \mathrm{ZnS} \sim 2$ at $365 \mathrm{~nm}$ and $\mathrm{ZCIS} / \mathrm{ZnS} \sim$ 0.544 at $450 \mathrm{~nm})$ and the $3 \mathrm{~mL}$ QD CHCl 3 solution was mixed with silicone resin $(0.4019 \mathrm{~g}$, OE-6630B:OE-6630A = 4:1). The QDs and silicone mixture was degassed under a vacuum to remove the $\mathrm{CHCl}_{3}$ and air bubbles. The final $\mathrm{ZnSe} / \mathrm{ZnS}$ QDs and ZCIS/ZnS QD-silicone resin mixture was coated on a $395 \mathrm{~nm}$-emitting nUV LED chip (non-molded $5.0 \times 5.0 \mathrm{~mm}^{2}$ SMD type). The white LED packages encapsulated with ZnSe/ZnS and ZCIS/ZnS-silicone resin were cured at $60^{\circ} \mathrm{C}$ for $60 \mathrm{~min}$, then at $110{ }^{\circ} \mathrm{C}$ for $60 \mathrm{~min}$.

Characterization. The PL and absorption spectra of the ZnSe-based QDs were collected with a Hitachi F-7000 spectrophotometer and a PerkinElmer LAMBDA 25 spectrophotometer, respectively. Transmission electron microscopy (TEM) was conducted with a Tecnai G2 F20 scanning transmission electron microscope operated at $200 \mathrm{kV}$ to investigate the size and morphologies of the QDs. The particle sizes of the ZnSe C QDs and ZnSe/ZnS C/S QDs were determined by measuring one hundred of the QDs in the TEM 
images. X-ray diffraction (XRD) was performed with a Bruker D8 ADVANCE operated at $40 \mathrm{kV}$ and $40 \mathrm{~mA}\left(\lambda_{\mathrm{CuK} \alpha}=1.5406 \AA\right)$ to analyze the crystal structure of the QDs. The absolute PL quantum yields (QYs) of the ZnSe C QDs and ZnSe/ZnS C/S QDs were measured with a QE-1100 quantum efficiency measurement system (Otsuka Electronics Co., Ltd., Osaka, Japan) using an integrating hemisphere. Optical properties, including electroluminescence (EL) spectra, Commission Internationale de l'Éclairage (CIE) color coordinates, color rendering index $\left(R_{\mathrm{a}}\right)$, and the correlated color temperature $\left(T_{\mathrm{c}}\right)$ of the white LEDs, were evaluated using an OPI-100 total luminous flux measurement system (Withlight Co., Ltd., Jeonju, Korea).

\section{Results and Discussion}

The growth of the ZnSe C QDs was investigated by absorption spectra, as shown in Figure 1a. The first absorption peak was observed at $407 \mathrm{~nm}$ for the aliquot taken at $5 \mathrm{~min}$ and continuously redshifted to $418 \mathrm{~nm}$ as the reaction time increased. This shift resulted from the increase in core size, and it indicated a size-dependent, electronic-energy band structure [33]. Consequently, a redshift in the absorption spectra of the ZnSe C QDs was observed with the growth of the $\mathrm{ZnSe}$ due to quantum confinement effects [33]. PL spectra also shifted from $413 \mathrm{~nm}$ to $425 \mathrm{~nm}$ with increasing reaction time. The absolute PL QY of the ZnSe C QDs was measured to be $19.4 \%$. As the reaction time increased, the bandwidth of the ZnSe C QDs became narrower. The full width at half-maximum (FWHM) of the PL band of the ZnSe C QDs was $15.5 \mathrm{~nm}$ for the aliquot taken at 5 min and $13.5 \mathrm{~nm}$ for the aliquot taken at $60 \mathrm{~min}$, which indicates that size focusing occurred during the growth of the ZnSe C QDs. The synthesized ZnSe C QDs exhibited narrow size distribution $(4.6 \pm 0.2 \mathrm{~nm}$, average size \pm standard deviation).
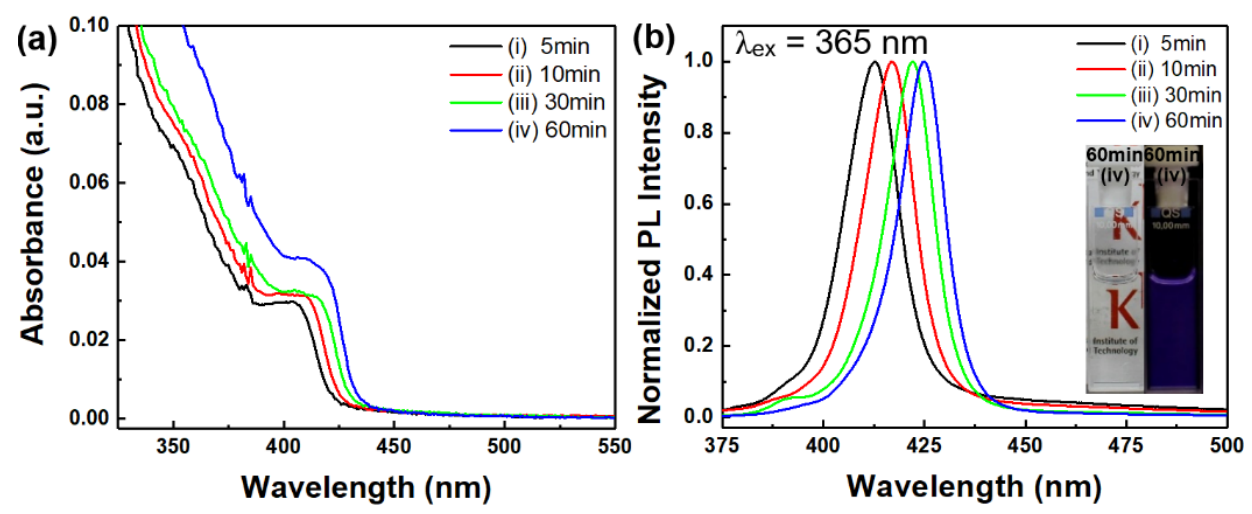

Figure 1. (a) Absorption and (b) PL spectra of the as-synthesized ZnSe C QDs as a function of reaction time ((i) $5 \mathrm{~min}$, (ii) $10 \mathrm{~min}$, (iii) $30 \mathrm{~min}$, and (iv) $60 \mathrm{~min}$ )). The inset in (b) shows photographs of the ZnSe C QD solution (reaction time was $60 \mathrm{~min}$ ) under indoor light (left) and UV light (right, $\lambda=365 \mathrm{~nm})$.

The photophysical properties of the synthesized ZnSe C QDs can be improved by the formation of a $\mathrm{ZnSe} / \mathrm{ZnS} \mathrm{C} / \mathrm{S}$ structure, since the $\mathrm{ZnS}$ shell decreases surface defects and increases confinement of the exciton [3,34]. The effect of ZnS shelling on the optical properties of the ZnSe QDs was investigated (Figure 2a,b). Figure 2a shows the absorption spectra of ZnSe C and ZnSe/ZnS C/S QDs. The formation of the ZnS shell on the ZnSe core decreased the surface defects of the ZnSe core [16]; thus, PL intensity increased, as shown in Figure 2b. The absolute PL QY of the ZnSe/ZnS C/S QDs was measured to be $37.4 \%$. The ZnSe/ZnS C/S QDs exhibited their first absorption peak at different wavelengths, depending on the reaction temperature of the $\mathrm{ZnSe} / \mathrm{ZnS} \mathrm{C} / \mathrm{S}$ QDs. The reaction temperature was increased from $310^{\circ} \mathrm{C}$ to $330^{\circ} \mathrm{C}$, and absorption peaks were observed at $421 \mathrm{~nm}$, $423 \mathrm{~nm}$, and $427 \mathrm{~nm}$ for the $\mathrm{ZnSe} / \mathrm{ZnS} \mathrm{C} / \mathrm{S}$ QDs synthesized at $310^{\circ} \mathrm{C}, 320^{\circ} \mathrm{C}$, and $330^{\circ} \mathrm{C}$, respectively (Figure 3a). Since increasing the reaction temperature affected nucleation and growth of the QDs, larger QDs could be synthesized at higher reaction temperatures and a 
redshift of the absorption band was observed due to the quantum confinement effect [23]. Figure $3 \mathrm{~b}$ shows that the PL intensity of the $\mathrm{ZnSe} / \mathrm{ZnS} \mathrm{C} / \mathrm{S}$ QDs synthesized at $310^{\circ} \mathrm{C}$ was higher than those of the $\mathrm{ZnSe} / \mathrm{ZnS} \mathrm{C} / \mathrm{S}$ QDs synthesized at $320^{\circ} \mathrm{C}$ and $330^{\circ} \mathrm{C}$. As the temperature was increased from $310^{\circ} \mathrm{C}$ to $320^{\circ} \mathrm{C}$ and $330^{\circ} \mathrm{C}$, PL intensity decreased. According to Peng's group, the PL QY of the QDs depends on the sizes of the QDs [35]. Thus, it is believed that, when the temperature is $320^{\circ} \mathrm{C}$, the size of the $\mathrm{ZnSe} / \mathrm{ZnS} \mathrm{C} / \mathrm{S}$ QDs is larger than the optimal size of the ZnSe/ZnS C/S QDs, which shows the best PL property. When the $\mathrm{ZnSe} / \mathrm{ZnS} \mathrm{C} / \mathrm{S}$ QDs were synthesized at $300^{\circ} \mathrm{C}$, blue light was hardly observed. As a consequence, the optimized reaction temperature in this study was $310^{\circ} \mathrm{C}$.
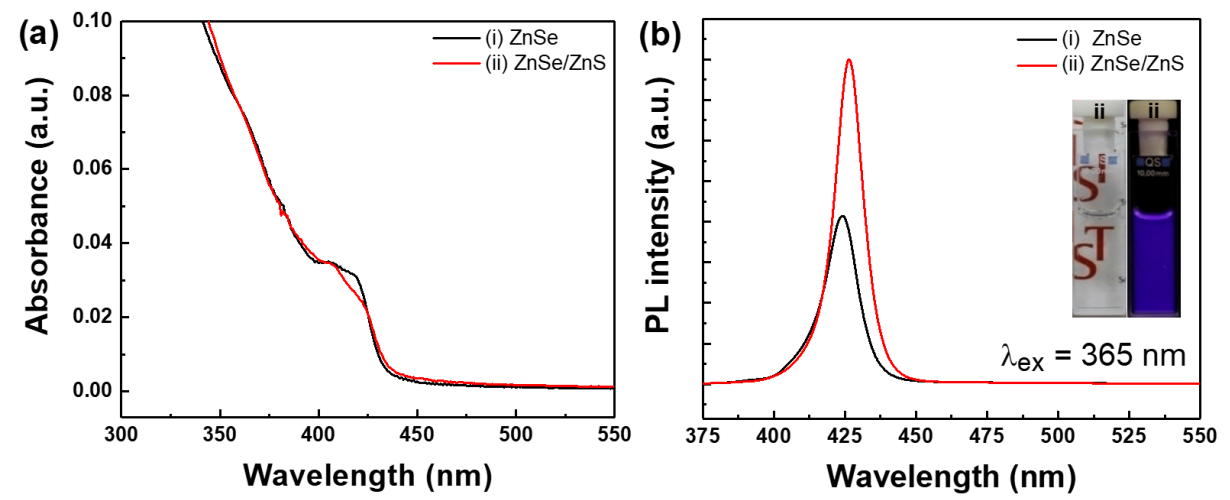

Figure 2. (a) Absorption and (b) PL spectra of (i) ZnSe C QDs and (ii) ZnSe/ZnS C/S QDs synthesized at $310{ }^{\circ} \mathrm{C}$. The inset in (b) shows photographs of the $\mathrm{ZnSe} / \mathrm{ZnS} \mathrm{C} / \mathrm{S}$ QD solution under indoor light (left) and UV light (right, $\lambda=365 \mathrm{~nm}$ ).
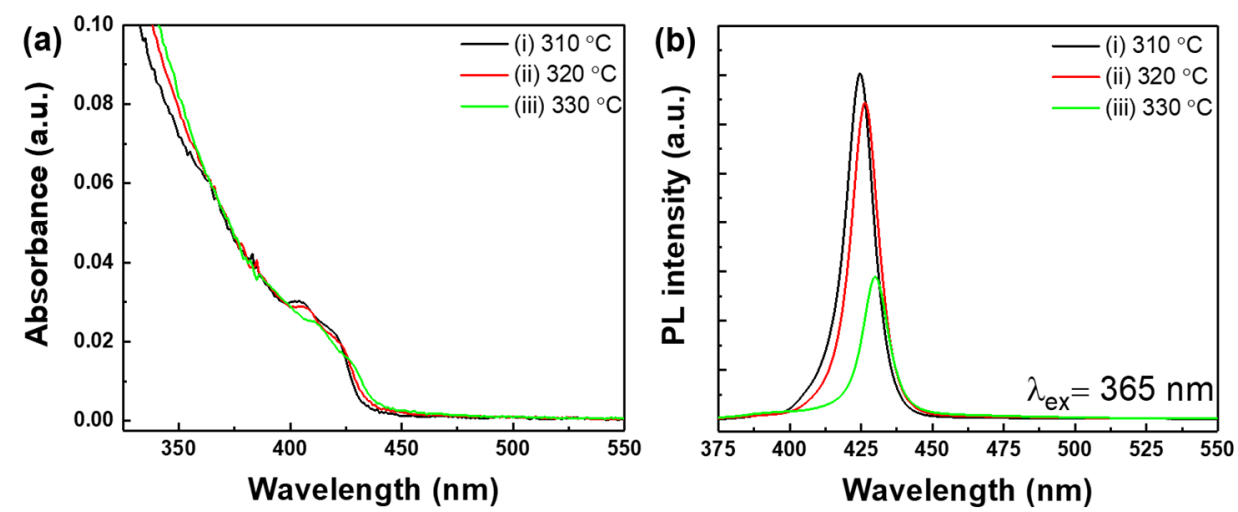

Figure 3. (a) Absorption and (b) PL spectra of the ZnSe/ZnS C/S QDs synthesized at (i) $310^{\circ} \mathrm{C}$, (ii) $320^{\circ} \mathrm{C}$, and (iii) $330{ }^{\circ} \mathrm{C}$, respectively.

In addition to spectroscopic studies, $\mathrm{XRD}$ patterns and TEM images were obtained to investigate the structure of the ZnSe C and ZnSe/ZnS C/S QDs in which ZnSe C was synthesized at $310^{\circ} \mathrm{C}$ for $1 \mathrm{~h}$ and the $\mathrm{ZnS}$ shell was formed by heat treatment at $310{ }^{\circ} \mathrm{C}$ for $50 \mathrm{~min}$. As shown in the XRD pattern, the peak positions of the ZnSe C QDs were in agreement with bulk ZnSe with a zinc blende structure (Figure 4a-i). Three obvious diffraction peaks located at $27.2^{\circ}, 45.3^{\circ}$, and $53.5^{\circ}$ corresponded to the diffraction peaks of the (111), (220), and (311) planes of zinc blende ZnSe, respectively. After the shelling procedure (Figure 4a-ii), the zinc blende structure remained and XRD peaks were slightly shifted to higher angles $\left(27.6^{\circ}, 46.1^{\circ}\right.$, and $\left.54.1^{\circ}\right)$ because $\mathrm{ZnS}$ has smaller lattice parameters than ZnSe [36]. The high degree of crystallinity was also confirmed by highresolution TEM (HR-TEM) images, shown in Figure $4 \mathrm{~b}$. The HR-TEM images and fast Fourier transformation (FFT) patterns of the ZnSe C and ZnSe/ZnS C/S QDs are shown in Figure $4 \mathrm{~b}$. The lattice fringes were separated by $d=0.32 \mathrm{~nm}$ for the ZnSe $C$ and the ZnSe/ZnS C/S QDs, which was consistent with the lattice spacings between the (111) 
planes of zinc blende ZnSe. The synthesized ZnSe/ZnS C/S QDs exhibited a narrow size distribution of $5.1 \pm 0.5 \mathrm{~nm}$ (average size \pm standard deviation).
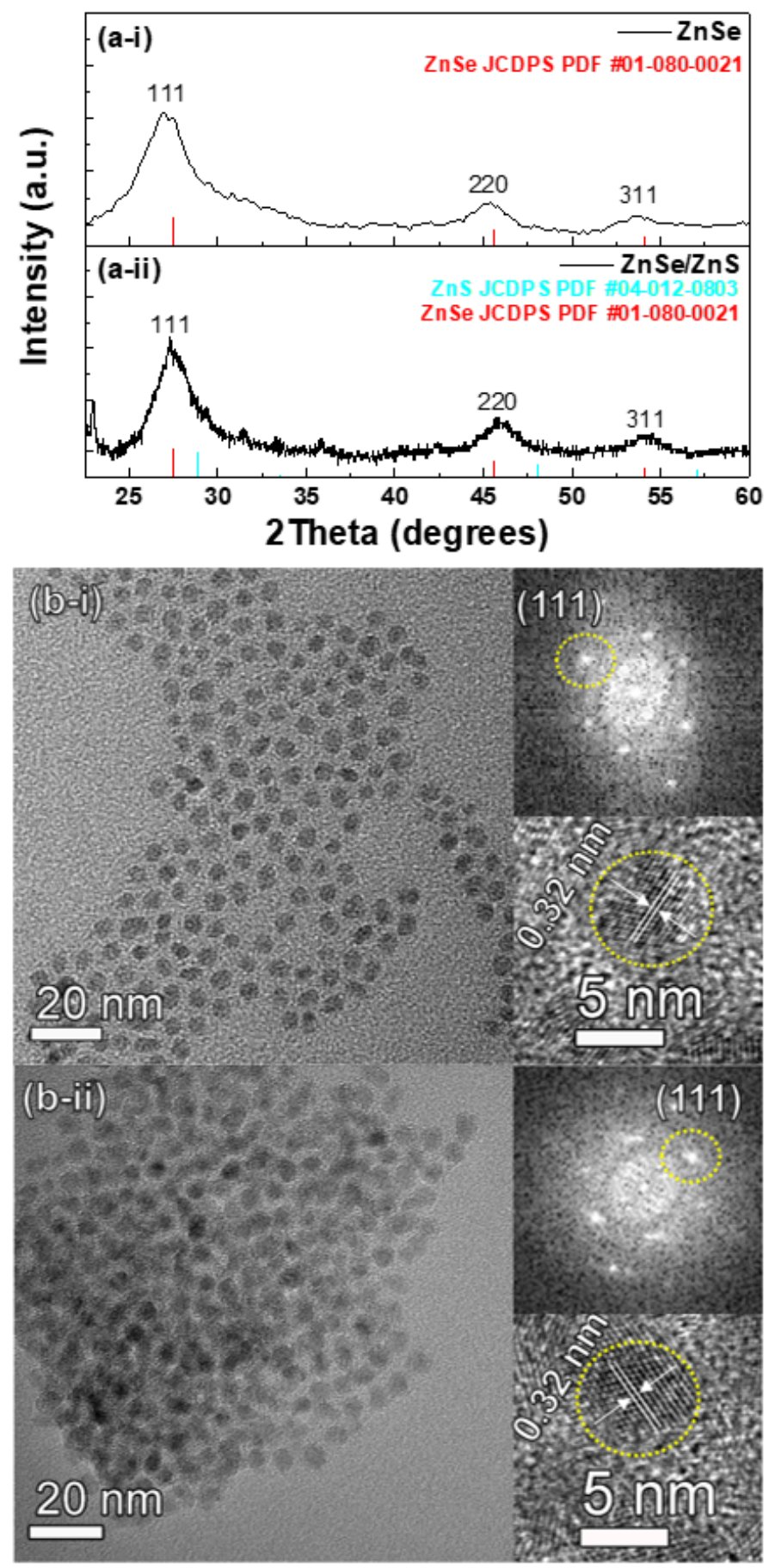

Figure 4. (a) XRD patterns and (b) TEM images of (i) ZnSe C QDs and (ii) ZnSe/ZnS C/S QDs. Lower insets in (b) show HR-TEM images of (i) ZnSe C QDs and (ii) ZnSe/ZnS C/S QDs and the upper insets in (b) show FFT patterns for the corresponding HR-TEM images.

nUV LED-pumped blue LEDs were fabricated with the ZnSe/ZnS C/S QDs. Figure 5 shows the optical properties of the fabricated blue LEDs, which were evaluated at $60 \mathrm{~mA}$. In the EL spectrum, two peaks were observed. One peak in the nUV region and the other peak in the blue region were attributed to the nUV LED and $\mathrm{ZnSe} / \mathrm{ZnS} \mathrm{C} / \mathrm{S}$ QDs, respectively. Blue light was emitted from the fabricated LED due to the strong EL peak in the blue 
spectral region (Figure 5a inset). Moreover, the CIE chromaticity diagram shows that the color coordinates of the emission light from the $\mathrm{ZnSe} / \mathrm{ZnS} \mathrm{C} / \mathrm{S}$ QD-converted LED were located in the blue region (Figure $5 b$ ).
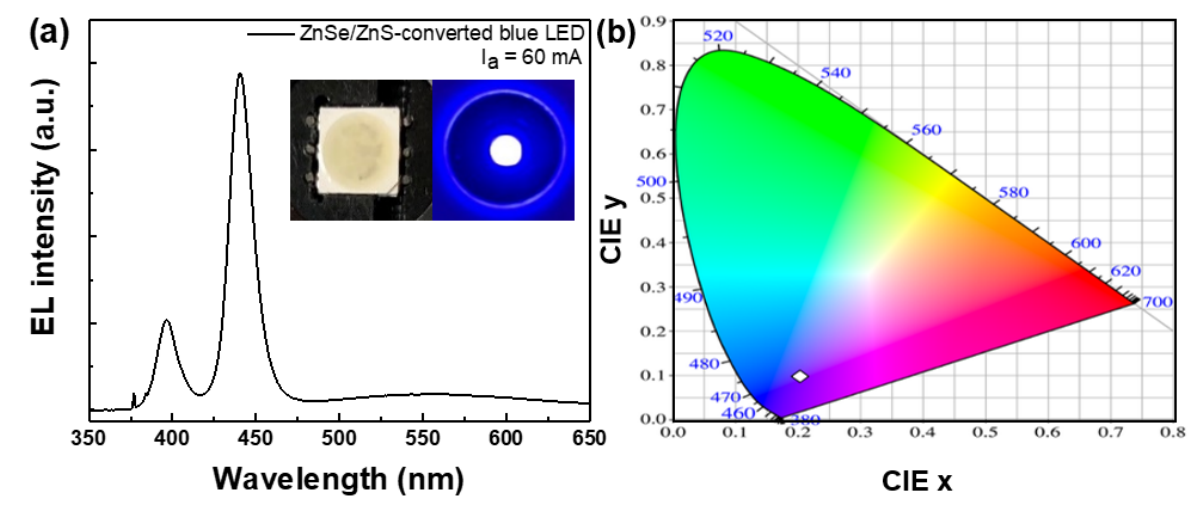

Figure 5. (a) EL spectra of the ZnSe/ZnS-converted blue LED at $60 \mathrm{~mA}$ and (b) CIE color coordinates of the ZnSe/ZnS-converted blue LED. The inset in (a) shows photographs of the ZnSe/ZnS-converted blue LED without (left) and with (right) applied current.

In addition to fabricating the $\mathrm{ZnSe} / \mathrm{ZnS} \mathrm{C} / \mathrm{S}$ QD-converted blue LED, ZnSe/ZnS $\mathrm{C} / \mathrm{S}$ QD-converted white LEDs were also fabricated. White light can be generated by combining blue-emitting ZnSe/ZnS C/S QDs with yellow-emitting QDs. We synthesized yellow-emitting ZCIS/ZnS C/S QDs by referring to the previous method with a slight modification [32]. As shown in Figure 6, the ZCIS/ZnS C/S QDs exhibited an absorption band in the blue spectral region and a broad PL band under $450 \mathrm{~nm}$ excitation. The ZCIS/ZnS C/S QDs showed a broad PL band peaking at $565 \mathrm{~nm}$ with a wide FWHM of $115.5 \mathrm{~nm}$, resulting in yellow luminescence. The PL QY of the yellow-light-emitting ZCIS/ZnS C/S QDs was measured at 83\%. The absorption band of the ZCIS/ZnS C/S QDs was well matched with the emission band of the ZnSe/ZnS C/S QDs. Thus, a combination of ZnSe/ZnS C/S QDs and ZCIS/ZnS C/S QDs can create white light.

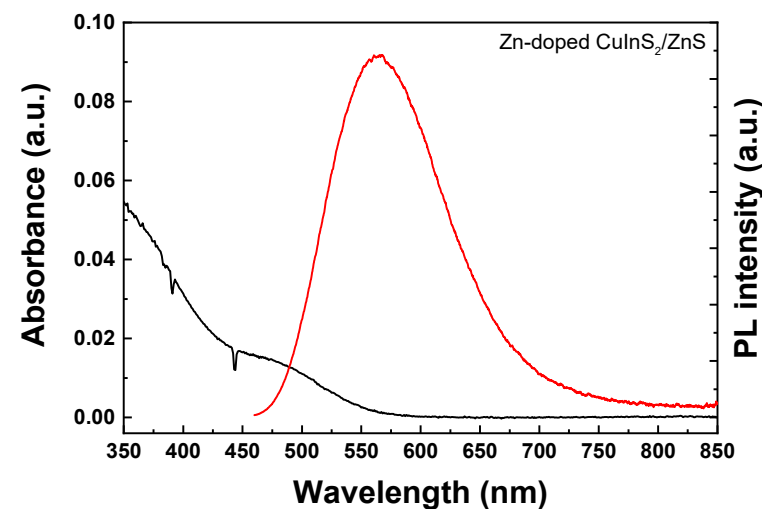

Figure 6. Absorption (black line) and PL (red line) spectra of Zn-doped CuInS $2 / Z n S C / S$ QDs.

In this study, to investigate the applicability of ZnSe/ZnS C/S QDs for warm white LEDs, which can be used in the lighting field, we fabricated warm white LEDs by combining an nUV LED chip, ZnSe/ZnS C/S QDs, and ZCIS/ZnS C/S QDs. Figure 7 shows the optical properties of the warm white LEDs, which were evaluated at $60 \mathrm{~mA}$. In the EL spectrum shown in Figure 7a, three peaks were observed. The peak in the nUV region is attributed to the nUV LED chip, and other peaks in the blue and yellow spectral regions are attributed to the ZnSe/ZnS C/S QDs and ZCIS/ZnS C/S QDs. Warm white light was emitted from the fabricated white LEDs due to a combination of characteristic emission peaks of the ZnSe/ZnS C/S QDs and ZCIS/ZnS C/S QDs (Figure 7a inset). When we 
investigated the luminous efficacy of the fabricated warm white LEDs, we determined it was $3.7 \mathrm{lmW}^{-1}$. Although this is not a high value, the luminous efficacy is affected by the efficiency of the nUV LED chip and coated QDs, etc. The luminous efficacy of white LEDs can be increased by using a highly efficient nUV LED chip and by enhancing the efficiency of the coated QDs, a topic of further study. The CIE color coordinates, correlated color temperature, and color rendering index of the warm white LED were $(0.4088,0.3987)$, $3488 \mathrm{~K}$ and 61.2 , respectively. The CIE chromaticity diagram shows that the chromaticity point of the white LEDs was located in the 'warm' white region, which was close to the standard illuminant $\mathrm{B}\left(T_{\mathrm{c}}=4870 \mathrm{~K}\right)$ (Figure $\left.7 \mathrm{~b}\right)$ [37].
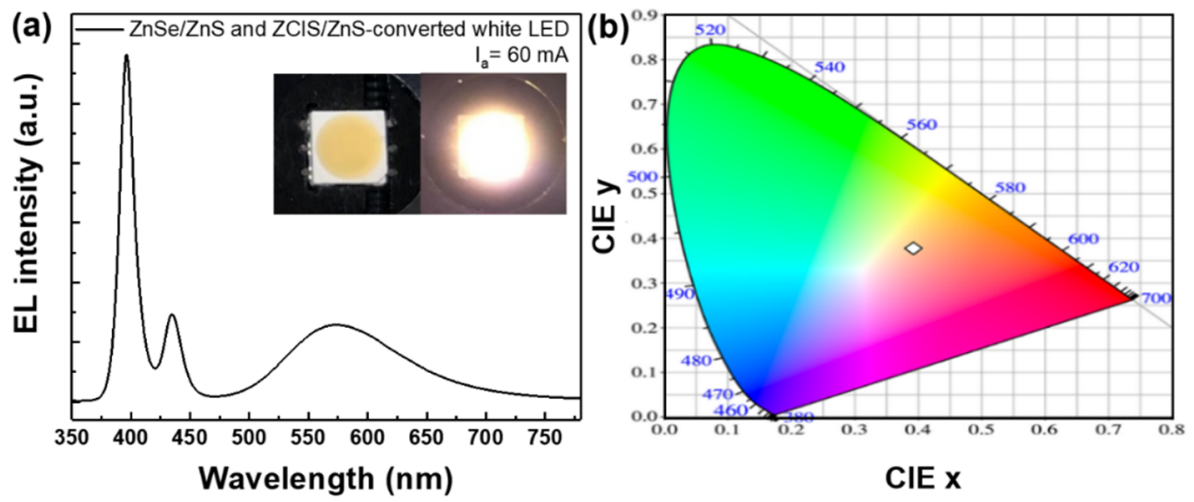

Figure 7. (a) EL spectra and (b) CIE color coordinates of the blue-emitting ZnSe/ZnS and yellowemitting ZCIS/ZnS QD-converted warm white LEDs under an applied current of $60 \mathrm{~mA}$. The inset shows photographs of the ZnSe/ZnS and ZCIS/ZnS QD-converted warm white LEDs (left) without and (right) with applied current.

\section{Conclusions}

In this study, eco-friendly, cadmium-free, blue-emitting ZnSe C QDs were successfully synthesized without phosphine precursors. The blue-emitting ZnSe C QDs were synthesized using a zinc-precursor injection method in a phosphine-free organic solvent at high temperature. The surfaces of the as-synthesized ZnSe C QDs were passivated with ZnS to reduce surface defects and increase confinement of the exciton for a higher PL QY. The ZnS shell was also formed on the $\mathrm{ZnSe}$ core without phosphine precursors. The $\mathrm{C} / \mathrm{S}$ structure of the $\mathrm{ZnSe} / \mathrm{ZnS}$ QDs was confirmed by XRD. The main XRD peaks of the ZnSe at $27.2^{\circ}$, $45.3^{\circ}$, and $53.5^{\circ}$ were shifted to higher angles due to the $\mathrm{ZnS}$ shell, which caused lattice compression and confirmed the formation of the $\mathrm{C} / \mathrm{S}$ structure. After the formation of the ZnS shell, the PL QY of the ZnSe increased from $19.4 \%$ to $37.4 \%$ and the ZnSe/ZnS C/S QDs emitted deep-blue light peaking at $425 \mathrm{~nm}$. By utilizing the ZnSe/ZnS C/S QDs, nUV LED-pumped blue LEDs and warm white LEDs were fabricated. The white LEDs fabricated by coating the blue-emitting ZnSe/ZnS C/S QDs and the yellow-emitting ZCIS/ZnS $\mathrm{C} / \mathrm{S}$ QDs on the nUV LED chip showed warm white light. These results indicate that the ZnSe/ZnS C/S QDs have good potential for white LED-based lighting applications.

Author Contributions: Conceptualization, H.S.J.; methodology, N.B. and J.J.; formal analysis, N.B., J.J., H.K. and H.S.J.; investigation, N.B., J.J., H.K., J.Y.B. and B.-K.J.; resources, J.Y.B. and H.S.J.; data curation, N.B. and H.S.J.; writing-original draft preparation, N.B. and H.S.J.; writing-review and editing, N.B., H.K. and H.S.J.; supervision, B.-K.J., H.S.J.; funding acquisition, H.K. and H.S.J. All authors have read and agreed to the published version of the manuscript.

Funding: This research was supported by the Future Key technology program (2E31181) by the Korea Institute of Science, the Materials Innovation Project (NRF-2020M3H4A3081791) funded by the National Research Foundation of Korea, and the National Research Foundation of Korea (NRF) grant funded by the Korea government (NRF- 2019R1A2C2088940).

Institutional Review Board Statement: Not applicable. 
Informed Consent Statement: Not applicable.

Conflicts of Interest: The authors declare no conflict of interest.

\section{References}

1. Alivisatos, A.P. Perspectives on the Physical Chemistry of Semiconductor Nanocrystals. J. Phys. Chem. 1996, 100, 13226-13239. [CrossRef]

2. Smith, A.M.; Nie, S. Semiconductor Nanocrystals: Structure, Properties, and Band Gap Engineering. Acc. Chem. Res. 2010, 43, 190-200. [CrossRef] [PubMed]

3. Todescato, F.; Fortunati, I.; Minotto, A.; Signorini, R.; Jasieniak, J.J.; Bozio, R. Engineering of Semiconductor Nanocrystals for Light Emitting Applications. Materials 2016, 9, 672. [CrossRef]

4. Fuke, N.; Hoch, L.B.; Koposov, A.Y.; Manner, V.W.; Werder, D.J.; Fukui, A.; Koide, N.; Katayama, H.; Sykora, M. CdSe QuantumDot-Sensitized Solar Cell with 100\% Internal Quantum Efficiency. ACS Nano 2010, 4, 6377-6386. [CrossRef]

5. Zhao, J.-Y.; Chen, G.; Gu, Y.-P.; Cui, R.; Zhang, Z.-L.; Yu, Z.-L.; Tang, B.; Zhao, Y.-F.; Pang, D.-W. Ultrasmall Magnetically Engineered $\mathrm{Ag}_{2} \mathrm{Se}$ Quantum Dots for Instant Efficient Labeling and Whole-Body High-Resolution Multimodal Real-Time Tracking of Cell-Derived Microvesicles. J. Am. Chem. Soc. 2016, 138, 1893-1903. [CrossRef]

6. Li, J.; Liang, Z.; Su, Q.; Jin, H.; Wang, K.; Xu, G.; Xu, X. Small Molecule-Modified Hole Transport Layer Targeting Low Turn-OnVoltage, Bright, and Efficient Full-Color Quantum Dot Light Emitting Diodes. ACS Appl. Mater. Interfaces 2018, 10, $3865-3873$. [CrossRef] [PubMed]

7. Kuehnel, M.F.; Sahm, C.D.; Neri, G.; Lee, J.R.; Orchard, K.L.; Cowan, A.J.; Reisner, E. ZnSe quantum dots modified with a $\mathrm{Ni}\left(\right.$ cyclam) catalyst for efficient visible-light driven $\mathrm{CO}_{2}$ reduction in water. Chem. Sci. 2018, 9, 2501-2509. [CrossRef]

8. Xu, Z.; Tang, X.; Liu, Y.; Zhang, Z.; Chen, W.; Liu, K.; Yuan, Z. CsPbBr 3 Quantum Dot Films with High Luminescence Efficiency and Irradiation Stability for Radioluminescent Nuclear Battery Application. ACS Appl. Mater. Interfaces 2019, 11, 14191-14199. [CrossRef]

9. Dabbousi, B.O.; Rodriguez-Viejo, J.; Mikulec, F.V.; Heine, J.R.; Mattoussi, H.; Ober, R.; Jensen, K.F.; Bawendi, M.G. (CdSe)ZnS Core-Shell Quantum Dots: Synthesis and Characterization of a Size Series of Highly Luminescent Nanocrystallites. J. Phys. Chem. B 1997, 101, 9463-9475. [CrossRef]

10. Yang, Y.; Zheng, Y.; Cao, W.; Titov, A.; Hyvonen, J.; Manders, J.R.; Xue, J.; Holloway, P.H.; Qian, L. High-efficiency light-emitting devices based on quantum dots with tailored nanostructures. Nat. Photon. 2015, 9, 259-266. [CrossRef]

11. Peng, X. An essay on synthetic chemistry of colloidal nanocrystals. Nano Res. 2009, 2, 425-447. [CrossRef]

12. Lee, C.Y.; Naik Mude, N.; Lampande, R.; Eun, K.J.; Yeom, J.E.; Choi, H.S.; Sohn, S.H.; Yoo, J.M.; Kwon, J.H. Efficient Cadmium-Free Inverted Red Quantum Dot Light-Emitting Diodes. ACS Appl. Mater. Interfaces 2019, 11, 36917-36924. [CrossRef]

13. Zhang, J.; Sun, W.; Yin, L.; Miao, X.; Zhang, D. One-pot synthesis of hydrophilic CuInS 2 and CuInS $2-Z n S$ colloidal quantum dots. J. Mater. Chem. C 2014, 2, 4812-4817. [CrossRef]

14. Terada, S.; Xin, Y.; Saitow, K.-i. Cost-Effective Synthesis of Silicon Quantum Dots. Chem. Mater. 2020, 32, 8382-8392. [CrossRef]

15. Zhang, Y.; Xiao, J.; Zhuo, P.; Yin, H.; Fan, Y.; Liu, X.; Chen, Z. Carbon Dots Exhibiting Concentration-Dependent Full-VisibleSpectrum Emission for Light-Emitting Diode Applications. ACS Appl. Mater. Interfaces 2019, 11, 46054-46061. [CrossRef] [PubMed]

16. Reiss, P. ZnSe based colloidal nanocrystals: Synthesis, shape control, core/shell, alloy and doped systems. New J. Chem. 2007, 31, 1843-1852. [CrossRef]

17. Wang, A.; Shen, H.; Zang, S.; Lin, Q.; Wang, H.; Qian, L.; Niu, J.; Song Li, L. Bright, efficient, and color-stable violet ZnSe-based quantum dot light-emitting diodes. Nanoscale 2015, 7, 2951-2959. [CrossRef]

18. Murray, C.B.; Norris, D.J.; Bawendi, M.G. Synthesis and characterization of nearly monodisperse CdE $(E=S$, Se, Te) semiconductor nanocrystallites. J. Am. Chem. Soc. 1993, 115, 8706-8715. [CrossRef]

19. Chen, H.S.; Wang, S.J.J.; Lo, C.J.; Chi, J.Y. White-light emission from organics-capped ZnSe quantum dots and application in white-light-emitting diodes. Appl. Phys. Lett. 2005, 86, 131905. [CrossRef]

20. Li, L.S.; Pradhan, N.; Wang, Y.; Peng, X. High Quality ZnSe and ZnS Nanocrystals Formed by Activating Zinc Carboxylate Precursors. Nano Lett. 2004, 4, 2261-2264. [CrossRef]

21. Kim, T.; Kim, K.-H.; Kim, S.; Choi, S.-M.; Jang, H.; Seo, H.-K.; Lee, H.; Chung, D.-Y.; Jang, E. Efficient and stable blue quantum dot light-emitting diode. Nature 2020, 586, 385-389. [CrossRef]

22. Han, C.-Y.; Lee, S.-H.; Song, S.-W.; Yoon, S.-Y.; Jo, J.-H.; Jo, D.-Y.; Kim, H.-M.; Lee, B.-J.; Kim, H.-S.; Yang, H. More Than 9\% Efficient ZnSeTe Quantum Dot-Based Blue Electroluminescent Devices. ACS Energy Lett. 2020, 5, 1568-1576. [CrossRef]

23. Shen, H.; Wang, H.; Li, X.; Niu, J.Z.; Wang, H.; Chen, X.; Li, L.S. Phosphine-free synthesis of high quality ZnSe, ZnSe/ZnS, and Cu-, Mn-doped ZnSe nanocrystals. Dalton Trans. 2009, 10534-10540. [CrossRef] [PubMed]

24. Zhang, L.-J.; Shen, X.-C.; Liang, H.; Chen, F.-Y.; Huang, H.-J. Phosphine-free synthesis of ZnSe:Mn and ZnSe:Mn/ZnS doped quantum dots using new Se and S precursors. New J. Chem. 2014, 38, 448-454. [CrossRef]

25. Banski, M.; Afzaal, M.; Malik, M.A.; Podhorodecki, A.; Misiewicz, J.; O’Brien, P. Special Role for Zinc Stearate and Octadecene in the Synthesis of Luminescent ZnSe Nanocrystals. Chem. Mater. 2015, 27, 3797-3800. [CrossRef]

26. Guidelli, E.J.; Lignos, I.; Yoo, J.J.; Lusardi, M.; Bawendi, M.G.; Baffa, O.; Jensen, K.F. Mechanistic Insights and Controlled Synthesis of Radioluminescent ZnSe Quantum Dots Using a Microfluidic Reactor. Chem. Mater. 2018, 30, 8562-8570. [CrossRef] 
27. Chen, H.-S.; Lo, B.; Hwang, J.-Y.; Chang, G.-Y.; Chen, C.-M.; Tasi, S.-J.; Wang, S.-J.J. Colloidal ZnSe, ZnSe/ZnS, and ZnSe/ZnSeS Quantum Dots Synthesized from ZnO. J. Phys. Chem. B 2004, 108, 17119-17123. [CrossRef]

28. Jang, H.S.; Won, Y.H.; Jeon, D.Y. Improvement of electroluminescent property of blue LED coated with highly luminescent yellow-emitting phosphors. Appl. Phys. B 2009, 95, 715-720. [CrossRef]

29. Li, F.; You, L.; Nie, C.; Zhang, Q.; Jin, X.; Li, H.; Gu, X.; Huang, Y.; Li, Q. Quantum dot white light emitting diodes with high scotopic/photopic ratios. Opt. Express 2017, 25, 21901-21913. [CrossRef]

30. Boonsin, R.; Barros, A.; Donat, F.; Boyer, D.; Chadeyron, G.; Schneider, R.; Boutinaud, P.; Mahiou, R. Optical Properties and Reliability Studies of Gradient Alloyed Green Emitting $(\mathrm{CdSe})_{\mathrm{x}}(\mathrm{ZnS})_{1-\mathrm{x}}$ and Red Emitting $\left(\mathrm{CuInS}_{2}\right)_{\mathrm{x}}(\mathrm{ZnS})_{1-\mathrm{x}}$ Quantum Dots for White Light-Emitting Diodes. ACS Photon. 2018, 5, 462-470. [CrossRef]

31. Jiang, T.; Shen, M.; Dai, P.; Wu, M.; Yu, X.; Li, G.; Xu, X.; Zeng, H. Cd-free Cu-Zn-In-S/ZnS quantum dots@SiO 2 multiple cores nanostructure: Preparation and application for white LEDs. Nanotechnology 2017, 28, 435702. [CrossRef] [PubMed]

32. Park, S.H.; Hong, A.; Kim, J.-H.; Yang, H.; Lee, K.; Jang, H.S. Highly Bright Yellow-Green-Emitting CuInS 2 Colloidal Quantum Dots with Core/Shell/Shell Architecture for White Light-Emitting Diodes. ACS Appl. Mater. Interfaces 2015, 7, 6764-6771. [CrossRef] [PubMed]

33. Toufanian, R.; Zhong, X.; Kays, J.C.; Saeboe, A.M.; Dennis, A.M. Correlating ZnSe Quantum Dot Absorption with Particle Size and Concentration. Chem. Mater. 2021, 33, 7527-7536. [CrossRef]

34. Reiss, P.; Protière, M.; Li, L. Core/Shell Semiconductor Nanocrystals. Small 2009, 5, 154-168. [CrossRef] [PubMed]

35. Qu, L.; Peng, X. Control of Photoluminescence Properties of CdSe Nanocrystals in Growth. J. Am. Chem. Soc. 2002, 124, 2049-2055. [CrossRef]

36. Fang, Z.; Li, Y.; Zhang, H.; Zhong, X.; Zhu, L. Facile Synthesis of Highly Luminescent UV-Blue-Emitting ZnSe/ZnS Core/Shell Nanocrystals in Aqueous Media. J. Phys. Chem. C 2009, 113, 14145-14150. [CrossRef]

37. Wysezecki, G.; Stiles, W.S. Color Science: Concepts and Methods, Quantitative Data and Formulae; John Wiley \& Sons, Inc.: New York, NY, USA, 1967. 